\title{
Correction to: Population genetic structure of lumpfish along the Norwegian coast: aquaculture implications
}

\author{
Ólöf Dóra Bartels Jónsdóttir ${ }^{1}$ • Julia Schregel ${ }^{2}$. \\ Snorre B. Hagen ${ }^{2}$ - Camilla Tobiassen ${ }^{2}$. \\ Siv Grethe Aarnes ${ }^{2}$ - Albert K. D. Imsland ${ }^{1,3}$
}

Published online: 26 October 2017

(C) Springer International Publishing AG 2017

\section{Correction to: Aquacult Int \\ https://doi.org/10.1007/s10499-017-0194-2}

The original version of this article unfortunately contained an error where the figure caption for Figures 3 and 4 was mixed.

The correct caption for those figures should read as follows:

Fig. 3 Relationships between geographical (km shortest waterway) and genetic distance [estimated as FST (1-FST)-1] among pairs of lumpfish samples along the Norwegian coastline. The dotted line shows the results of non-significant $(\mathrm{y}=1 \mathrm{E}-06 \mathrm{x}+0.0152$, $\left.\mathrm{R}^{2}=0.0043, P>0.9\right)$ regression between geographic and genetic distance.

Fig. 4 Bayesian cluster analyses performed in STRUCTURE (Pritchard et al. 2000) on lumpfish samples from six sample localities. Each vertical bar represents an individual, whilst colours denote inferred clusters. The y-axis indicates the probability of an individual belonging to a particular cluster.

The online version of the original article can be found at https://doi.org/10.1007/s10499-017-0194-2

Albert K. D. Imsland

albert.imsland@akvaplan.niva.no

1 Akvaplan-niva, Iceland Office, Akralind 4, 201 Kópavogur, Iceland

2 Norwegian Institute of Bioeconomy Research, Svanhovd, 9925 Svanvik, Norway

3 Department of Biology, University of Bergen, High Technology Centre, 5020 Bergen, Norway 